\title{
CONFORMATIONAL ANALYSIS AND MOLECULAR MODELING OF CHOLESTERIC LIQUID CRYSTAL POLYESTERS BASED ON XRD, RAMAN, AND TRANSITION THERMAL ANALYSIS
}

\author{
J. Fayos , S. Sánchez-Cortés , C. Marco \& M. Pérez-Méndez
}

To cite this article: J. Fayos , S. Sánchez-Cortés , C. Marco \& M. Pérez-Méndez (2001) CONFORMATIONAL ANALYSIS AND MOLECULAR MODELING OF CHOLESTERIC LIQUID CRYSTAL POLYESTERS BASED ON XRD, RAMAN, AND TRANSITION THERMAL ANALYSIS, Journal of Macromolecular Science, Part B, 40:3-4, 553-576, DOI: 10.1081/MB-100106177

To link to this article: https://doi.org/10.1081/MB-100106177

Published online: 07 Feb 2007.

Submit your article to this journal ¿

Џ Article views: 49

Citing articles: 5 View citing articles ๘ 


\title{
CONFORMATIONAL ANALYSIS AND MOLECULAR MODELING OF CHOLESTERIC LIQUID CRYSTAL POLYESTERS BASED ON XRD, RAMAN, AND TRANSITION THERMAL ANALYSIS
}

\author{
J. Fayos, ${ }^{1}$ S. Sánchez-Cortés, ${ }^{2}$ C. Marco, ${ }^{3}$ \\ and M. Pérez-Méndez ${ }^{3, *}$ \\ ${ }^{1}$ Instituto Rocasolano, CSIC, Madrid, Spain \\ ${ }^{2}$ Instituto de Estructura de la Materia, CSIC, Madrid, Spain \\ ${ }^{3}$ Departamento de Física e Ingeniería, \\ Instituto de Ciencia y Tecnología de Polímeros, CSIC, \\ Juan de la Cierva, 3. 28006 Madrid, Spain
}

\begin{abstract}
Molecular modeling of the cholesteric liquid crystal polyester poly[oxy(1,2-dodecane)oxycarbonyl-1,4-phenyleneoxycarbonyl-1,4-phenylenecarbonyloxy-1,4-phenylenecarbonyl] (PTOBDME), $\left[\mathrm{C}_{34} \mathrm{H}_{36} \mathrm{O}_{8}\right]_{n}$, synthesized in our laboratory and thermally characterized by differential scanning calorimetry (DSC), was performed to explain both its cholesteric mesophase and $3 \mathrm{D}$ crystalline structure. Conformational analysis (CA) was run for the monomer both by systematic search and with molecular dynamics (MD) simulations. Minima energy conformers were "polymerized" with Cerius ${ }^{2}$ and helical, cholesteric molecules were obtained in all cases. Our models agree with the chiral behavior observed by X-ray diffraction (XRD), thermooptical analysis (TOA) and circular dichroism (CD) experiments. Crystal packing of the polymer molecules were simulated in cells with parameters $\mathbf{a}$ and $\mathbf{b}$ obtained from experimental powder X-ray diffraction patterns and $\mathbf{c}$ calculated from the translational repetitive unit during the theoretical polymerization. Recalculated X-ray powder diffraction patterns of our models matched the ob-
\end{abstract}

\footnotetext{
*Corresponding author. Fax: +34-1-562-1829; E-mail: perezmendez@ictp.csic.es
} 
served ones. Morphology simulation from those crystal models is in good agreement with the crystals observed by optical microscopy. We have also modeled the self-associating nature of those polyesters when dispersed in aqueous media. Simulation of our models surrounded by different solvents, such as water and chloroform, were performed by calculating their interaction energies, coordination numbers, and mixing energies, applying Monte Carlo simulation techniques based on the Flory-Huggins theory. These results were compared with their experimental vibrational Fourier transform (FT)-Raman spectra in the regions in which structural marker bands of the polymer appear.

Key Words: Cholesteric liquid crystals; FT Raman; Solvent effect; Structure simulation; XRD.

\section{INTRODUCTION}

A synthesis method previously reported for high molecular weight liquid crystal polyesters based on polycondensation of mesogenic monomers [1] was followed for the synthesis of PTOBEE, $\left[\mathrm{C}_{26} \mathrm{H}_{20} \mathrm{O}_{8}\right]_{n}$. It was obtained as cholesteric, although synthesized from the racemic mixture of the involved DL-1,2butanediol. Stereoselective solubilization of the negative enantiomer during its decantation in toluene was claimed to be the reason for this achievement $[1,2]$.

We have obtained the same result for the thermotropic liquid crystal poly[oxy(1,2-dodecane)oxycarbonyl-1,4-phenyleneoxycarbonyl-1,4-phenylenecarbonyloxy-1,4-phenylenecarbonyl] (PTOBDME) $\left[\mathrm{C}_{34} \mathrm{H}_{36} \mathrm{O}_{8}\right]_{n}$, which has also been obtained as chiral, cholesteric [3], although synthesized from the racemic mixture of DL-1,2-dodecanediol.

In this article, we present the details for its structural characterization by thermoanalysis, X-ray diffraction (XRD), circular dichroism (CD), and Fourier transform (FT)-Raman spectroscopy. Molecular modeling based on conformational analysis (CA) and XRD analysis were used to try to explain its mesophase and crystalline behavior.

\section{EXPERIMENTAL}

\section{Synthesis of Cholesteric PTOBDME}

PTOBDME was synthesized in our laboratory according to a method previously reported $[1,3]$ by polycondensation of $4-4$-(terephthaloyldioxydibenzoic chloride) (TOBC) and a racemic mixture of DL-1,2-dodecanediol from MerckSchuchardt (Hohenbrunn, Germany).

Although synthesized from a racemic mixture of the diol involved, as obtained it is cholesteric and chiral in nature [3]. It was characterized as -PTOBDME, with $[\alpha]_{589}^{25}=-1.43(1.538 \mathrm{gr} / 100 \mathrm{ml}$, toluene $)$. 


\section{Characterization of Cholesteric PTOBDME}

The structure of PTOBDME was determined as shown in the structure below by ${ }^{1} \mathrm{H}$ and ${ }^{13} \mathrm{C}$ nuclear magnetic resonance (NMR). Spectra were registered in $\left(\mathrm{CD}_{3}\right)_{2} \mathrm{SO}$ at $80^{\circ} \mathrm{C}$ in a Varian $300-\mathrm{MHz}$ spectrometer.

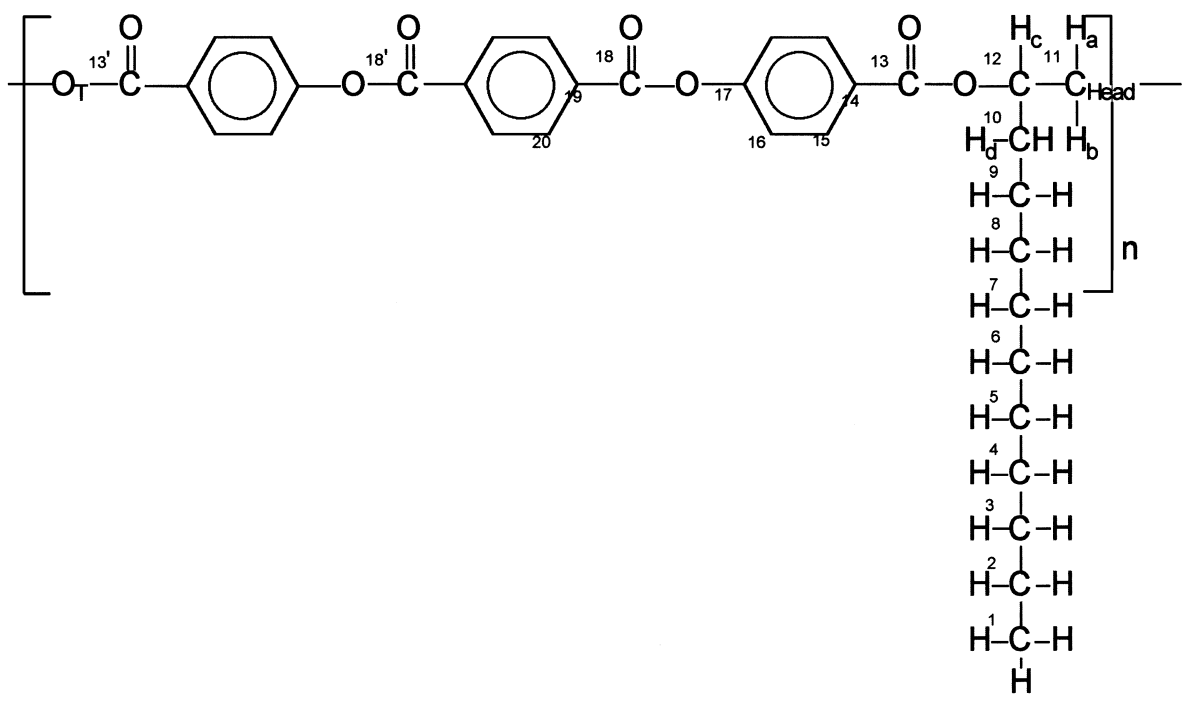

Thermal stability was studied on a Mettler TA4000-TG50 at a heating rate of $10^{\circ} \mathrm{C} / \mathrm{min}$ with nitrogen purge (Praxair, Madrid, Spain), and thermal transitions were observed by differential scanning calorimetry (DSC) in a Mettler TA4000/DSC30/TC11 calorimeter by a series of heating/cooling cycles in a temperature range between $10^{\circ} \mathrm{C}$ and $280^{\circ} \mathrm{C}$ at $10^{\circ} \mathrm{C} / \mathrm{min}$.

Circular dichroism was measured in a Jasco J-720 spectropolarimeter between 240 and $400 \mathrm{~nm}$. Thin solid films were prepared at $250^{\circ} \mathrm{C}$ and smoothly sheared to orient the sample. Spectra were registered after every $90^{\circ}$ rotation of the sample.

Simultaneous wide-angle X-ray scattering/small-angle X-ray scattering (WAXS/SAXS) spectra were obtained with the synchrotron radiation source at HASYLAB (DESY, Hamburg). Beam radiation $\lambda \mathrm{Cu}_{\mathrm{K} \lambda}=1.54 \AA$ was monochromatized by a bent germanium single crystal. Two linear one-dimensional detectors were used. The Interactive Data Manipulation Package OTOKO (C. Boulin, R. Kempf, M. H. J. Koch, and S. M. McLaughlin, 1986) was used to normalize, evaluate, and display raw one-dimensional data.

The modeling work was performed on a Silicon Graphics O2-5000 running IRIX $^{\circledR}$, version 6.3. The software used on this platform was Cerius ${ }^{2}-4.5$ supplied by Molecular Simulation, Incorporated, Instrument (Burlington, MA).

FT-Raman spectra were obtained using an RFS 100/S Bruker spectrophotometer. The 1064-nm line, provided by a Nd:YAG laser, was used. Resolution was set at $4 \mathrm{~cm}^{-1}$, and a $180^{\circ}$ geometry was employed. The output laser power 
was $150 \mathrm{~mW}$ for solid samples and $300 \mathrm{~mW}$ for the solutions. Solid samples were recorded in a brass holder, whereas for the liquid samples, 5-mm optical path quartz cells were employed. The FT-Raman spectra were the result of 1000 scans recorded over $20 \mathrm{~min}$.

\section{RESULTS AND DISCUSSION}

The thermal stability curve of PTOBDME is shown in Fig. 1 . At $280^{\circ} \mathrm{C}$, weight loss due to thermal decomposition begins to be observed. The DSC analysis (Fig. 2) shows a broad peak, in the heating range, centered at $67^{\circ} \mathrm{C}$ assigned to $T_{\mathrm{g}}$. A slight change of the baseline at about $90^{\circ}$ with a negligible enthalpy could be due to some crystalline arrangement over the glass transition. A sharp endothermic peak at $235^{\circ} \mathrm{C}$ is assigned to the transition from crystal to liquid crystal. Two broad and small peaks centered at $168^{\circ} \mathrm{C}$ and $197^{\circ} \mathrm{C}$, respectively, in the crystal stability yield are also observed. The high exothermic peak appearing at $149^{\circ} \mathrm{C}$ when cooling is interpreted as due to a crystallization process from the mesophase state. Degradation to shorter molecular chains precedes the isotropic state.

Circular dichroism obtained for oriented thin films of PTOBDME rotated every $90^{\circ}$ is shown in Fig. 3. It exhibits the exciton coupling effect, present when more than two chromophores of $\pi$-electron systems, independently involved in an optically active molecule, strongly correlate with each other. The observed curves change their sign with the sample rotation, probably due to the orientation of the different coils or antipode stereostructures with the opposite CD sign. These profiles match the calculated CD for a "spiral staircase" geometry well [4].

\section{X-Ray Analysis}

Figures 4 and 5 show XRD patterns of PTOBDME registered during heating and cooling ranges, respectively, with a synchrotron radiation source. Two XRD peaks, at $2 \theta \approx 16^{\circ}\left(\mathbf{d}_{100}=5.5 \AA\right)$ and $24^{\circ}(3.71 \AA)$, always present in the entire temperature range, were assigned to the cholesteric mesophase. A third one at $2 \theta \approx 19^{\circ}\left(\mathbf{d}_{010}=4.7 \AA\right)$ and a small one at $2 \theta \approx 22.5^{\circ}(3.95 \AA)$, disappearing at $240^{\circ} \mathrm{C}$ during the heating range and appearing again at about $150^{\circ} \mathrm{C}$ while cooling, were interpreted as due to presence of three-dimensional (3D) order. The crystalline stability temperature field is in agreement with the DSC curves. This means a cholesteric mesophase is always present and coexists with crystalline phase in the crystal stability temperature range.

\section{Molecular Modeling and Conformational Analysis of PTOBDME Monomer Unit}

Molecular modeling of PTOBDME monomer was performed by $\mathrm{Ce}$ rius $^{2}$ _4.5. The Dreiding-II force field was loaded, and partial atomic charges 


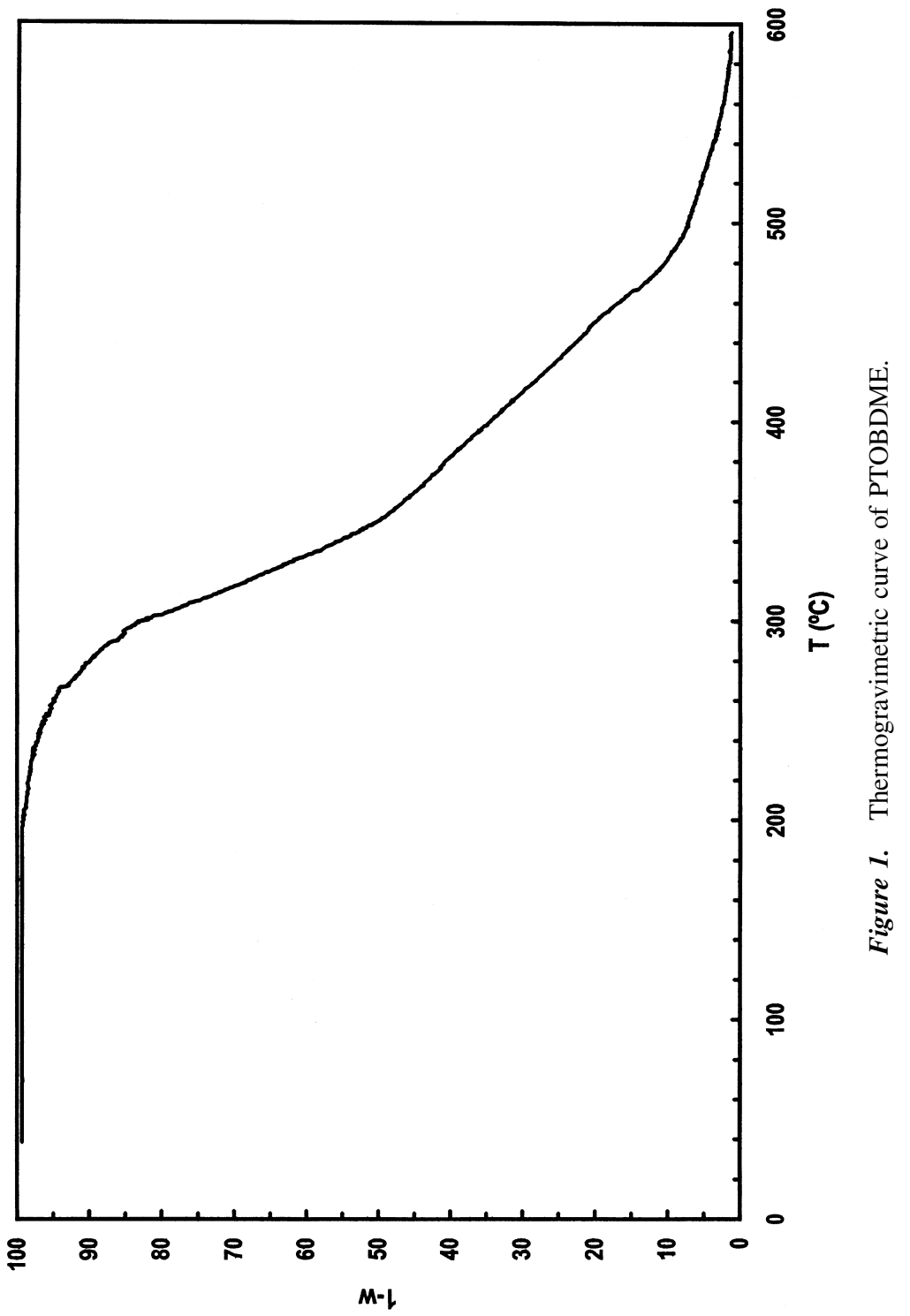




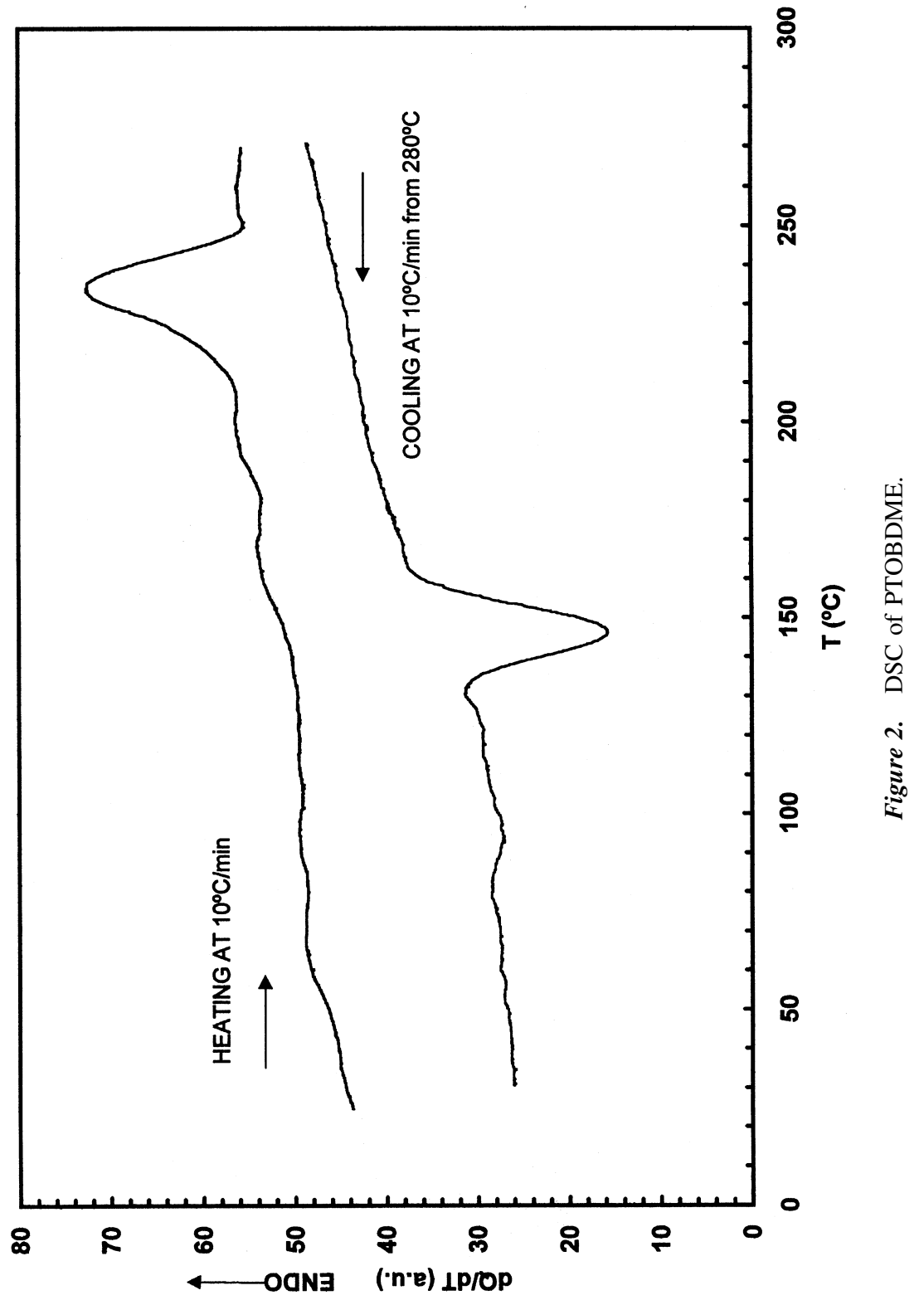




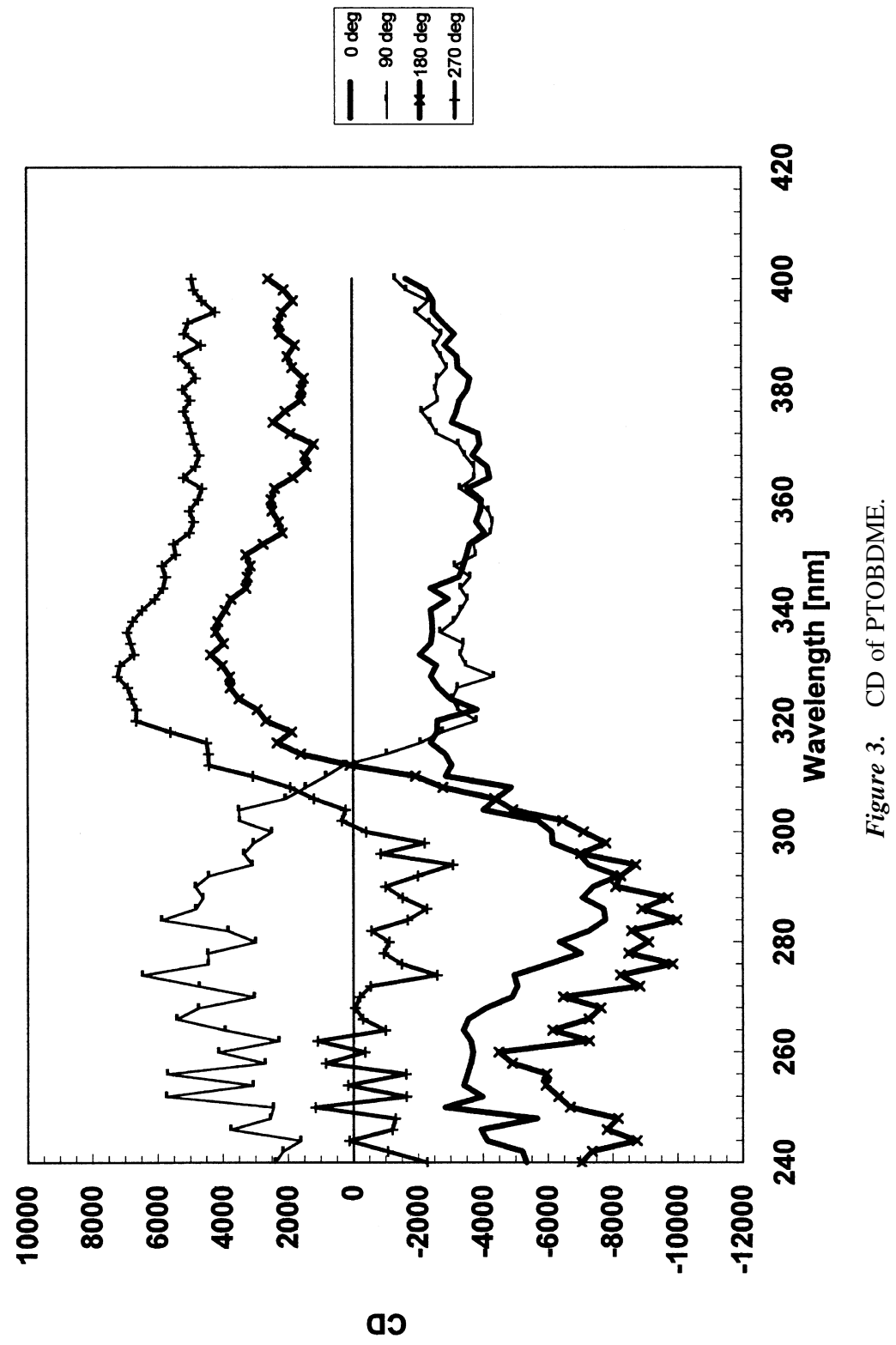




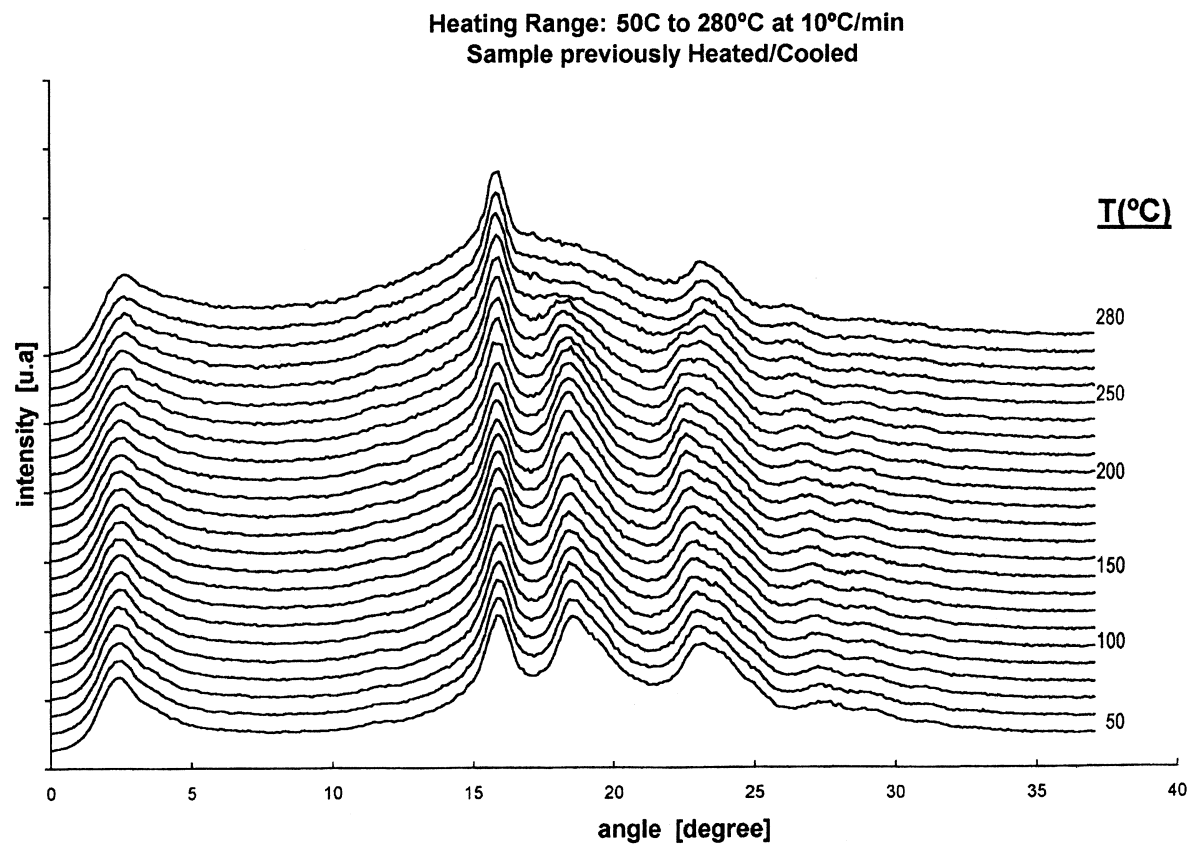

Figure 4. WAXS for PTOBDME in the heating range.

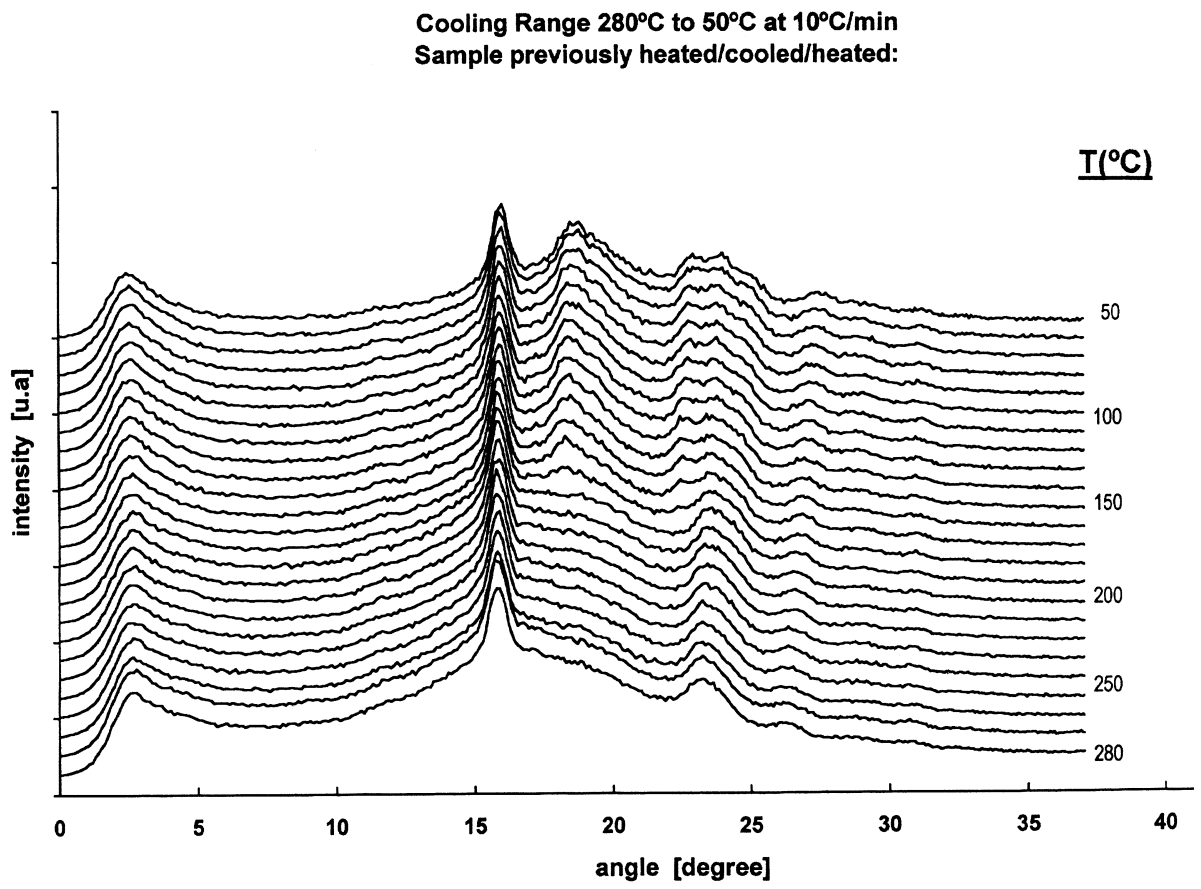

Figure 5. WAXS for PTOBDME in the cooling range. 
were calculated by the charge-equilibration method. Head $\left(\mathrm{C}_{\mathrm{H}}\right)$ and tail $\left(\mathrm{O}_{\mathrm{T}}\right)$ atoms were defined within the monomer. The presence of a chiral $\mathrm{C}^{*}$ atom was also considered and defined rectus in our models. Energy was then minimized. The molecular scheme of the monomer with $R=\left(\mathrm{CH}_{2}\right)_{9} \mathrm{CH}_{3}$, is

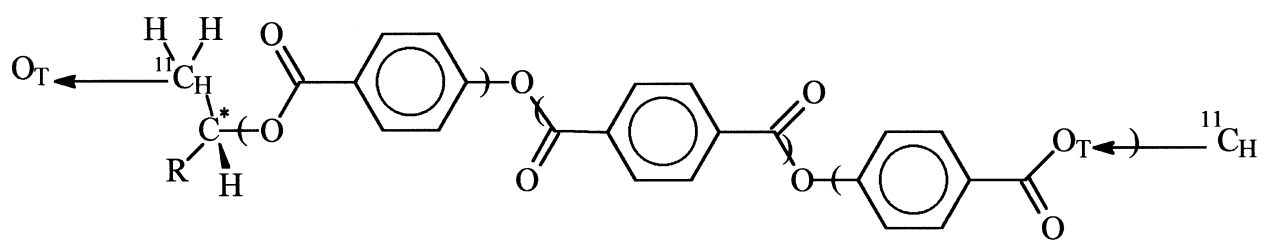

where the extended length between $\mathrm{C}_{\mathrm{H}}$ and $\mathrm{O}_{\mathrm{T}} \approx 23 \AA$.

Energetic terms for torsions and Coulomb and Van der Waals interactions were included in the CA of PTOBDME. We had observed that the interaction between mobile atoms on both sides of one benzene ring were negligible in the case of PTOBEE, $\left[\mathrm{C}_{26} \mathrm{H}_{20} \mathrm{O}_{8}\right]_{n}$, with a shorter lateral chain perpendicular to the mesogen [5]. Then, we made separately independent CA for the two torsions on each terephthalate ester group (bridge) of the mesogen and for the torsions within the flexible spacer (head). Consequently, a simplified model for the mesogen could be reduced in PTOBDME to the three articulated planes I, II, and III, limited by parentheses in the molecular scheme above, connected by ester groups, where torsions $\mathrm{CO} 1$ and $\mathrm{CBO} 1$ (or $\mathrm{CO} 2$ and $\mathrm{CBO} 2$ ) were the independent variables for CA.

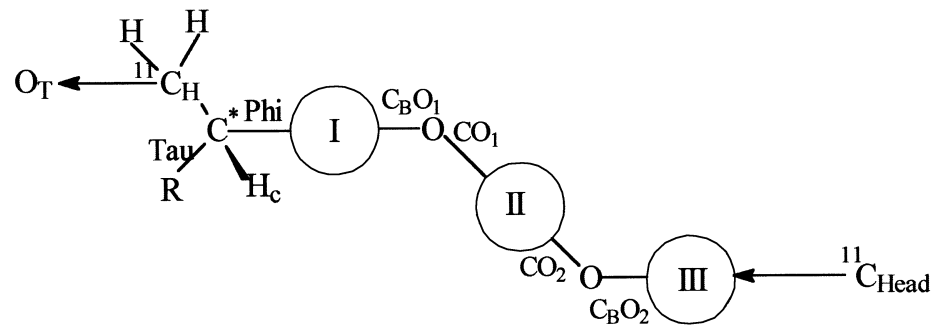

Four other independent torsions were defined for the CA within the flexible spacer, along the main chain (head): Phi, which defines the head orientation with respect to the mesogen; Tau, which determines the lateral chain orientation to the mesogen; the torsion $\mathrm{CO}$ along the $\mathrm{C}_{\text {carbonyl }} \mathrm{O}_{\text {ester }}$ bond (i.e., $\mathrm{C}^{13}$ in Structure 1), close to $180^{\circ}$; and $\mathrm{C}^{*}-\mathrm{C}_{\mathrm{H}}$.

Systematic CA were performed for the two torsions (CO1, CBO1) on one terephthalate ester bridge. Four equienergetic minima, about $74 \mathrm{kcal} / \mathrm{mol}$, were observed in the maps (CO, CBO) (Fig. 6) at points A $\left(164^{\circ},-44^{\circ}\right), \mathbf{B}\left(-164^{\circ}\right.$, $\left.44^{\circ}\right), \mathbf{C}\left(164^{\circ}, 141^{\circ}\right), \mathbf{D}\left(-164^{\circ},-141^{\circ}\right)$, very close $\left(\delta<5^{\circ}\right)$ to those found for PTOBEE but with a shorter lateral chain. Figure 6 also shows other secondary 

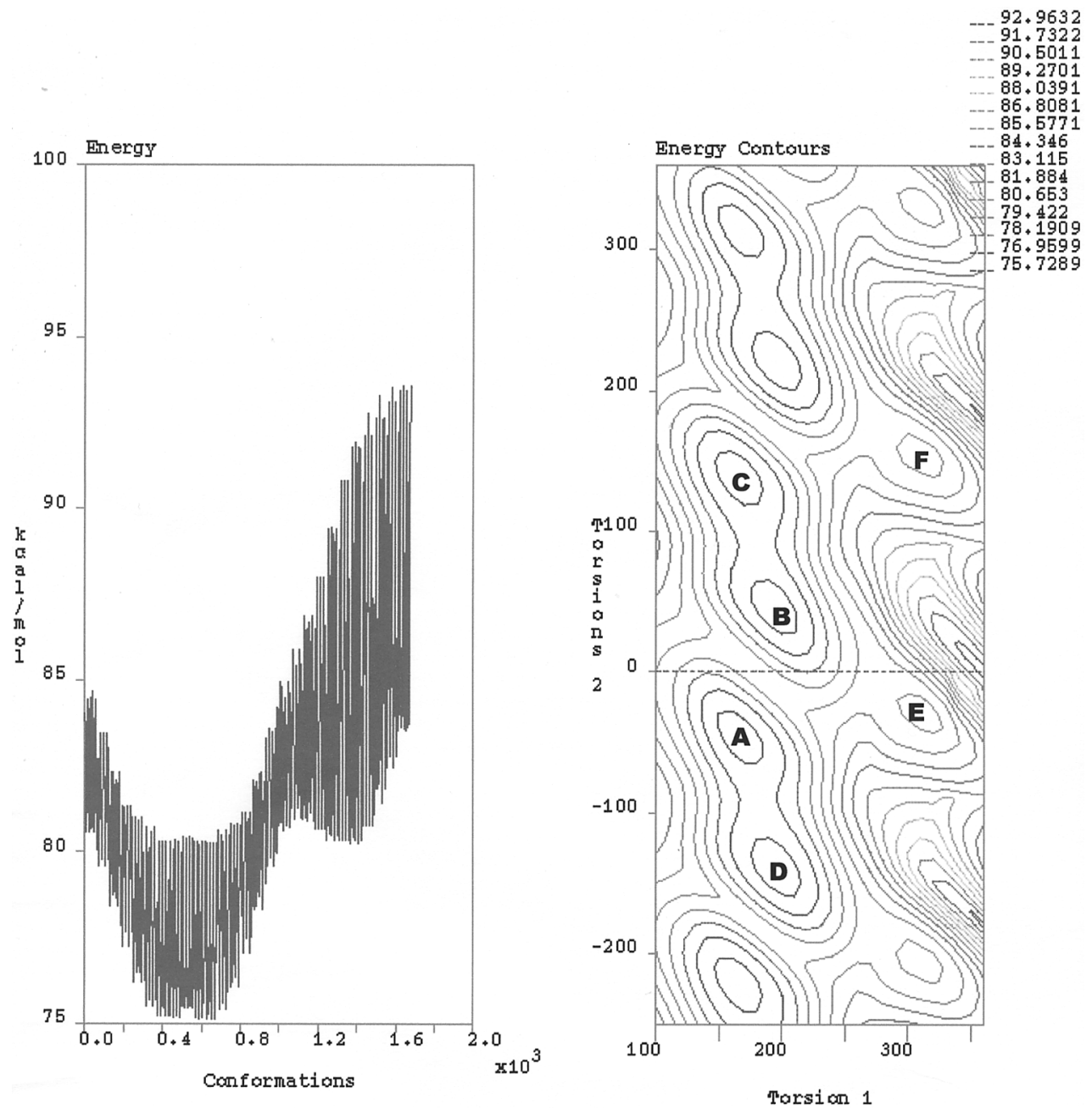

Figure 6. Systematic conformational search map for torsions: $1=\mathrm{CO}, 2=\mathrm{CBO}$.

minima, $\mathbf{E}\left(-42^{\circ},-36^{\circ}\right)$ and $\mathbf{F}\left(41^{\circ}, 144^{\circ}\right)$ with $\mathrm{E}=80 \mathrm{kcal} / \mathrm{mol}[30 \%$ higher with respect to the maximum high at $(0,0)]$. The same results were obtained in the $\mathrm{CA}$ of the second terephthalate ester group with two torsions $(\mathrm{CO} 2, \mathrm{CBO} 2)$.

The lowest energy conformations for the mesogen would all be combinations: $\mathrm{AA}, \mathrm{AB}, \ldots$, with $E=74 \mathrm{kcal} / \mathrm{mol}$ and with molecular T-shape. Due to the conformational map symmetry, only four different solutions exist: conformer AA with two successive rotations of about $+60^{\circ}$ of planes I, II, and III along the main-chain axis, with formation of a triangular helical cross section. Conformer $\mathrm{AB}$, in which rotation through the $\mathrm{O} 2$ bridge is about $-60^{\circ}$ against the about $+60^{\circ}$ through $\mathrm{O} 1$; hence, planes I and III became parallel. The other two conformers are the enantiomers of $\mathrm{AA}$ and $\mathrm{AB}$. Figure $7 \mathrm{a}$ shows the conformation $\mathrm{AB}$ with a T-shape. 


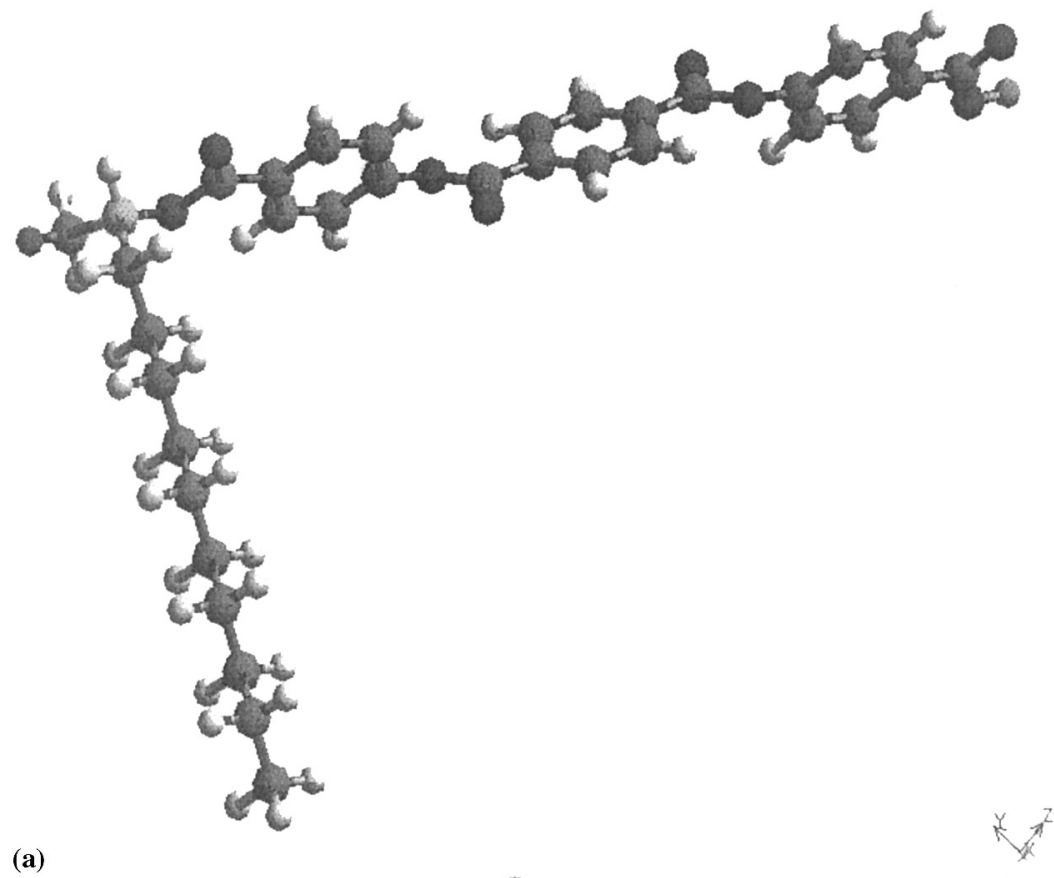

(a)

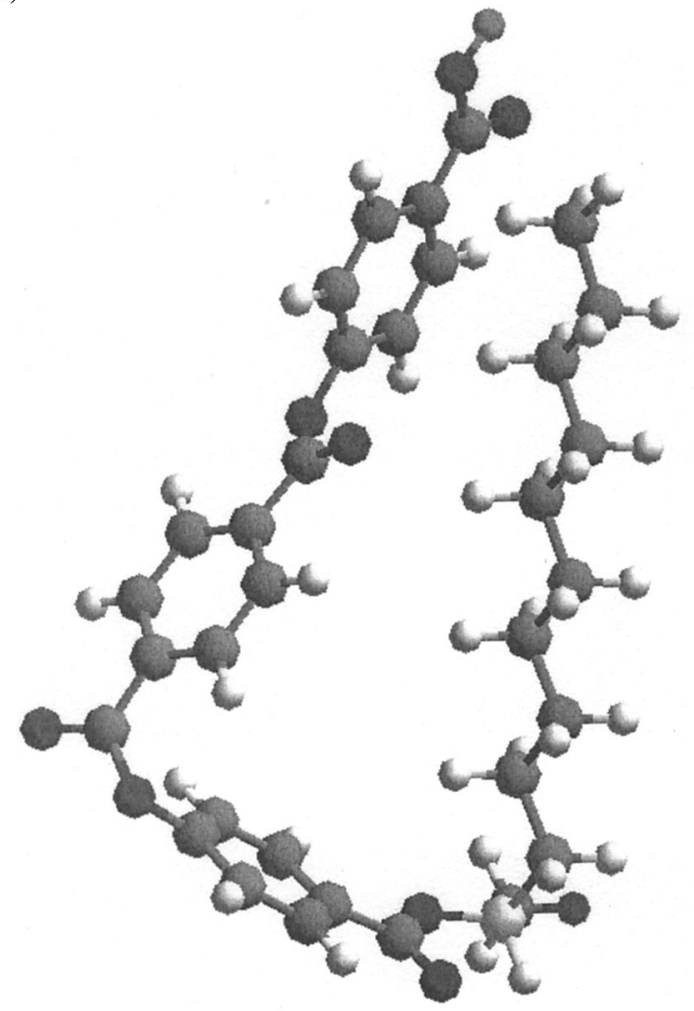

(b)

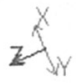

Figure 7. (a) PTOBDME monomer with conformation AB; (b) U-shaped monomer with conformation EB. 
Molecular models of the monomers with the lowest energy torsion values (from Fig. 6) were fully minimized in energy. After minimization, the same torsional values were found for the terephthalate ester group located far from the lateral chain. Instead, the terephthalate ester group closer to the lateral chain also adopted torsion values corresponding to the secondary energy minima observed in Fig. 6, approaching the mesogen parallel to the lateral chain in a U-shape. Figure $7 \mathrm{~b}$ shows this effect of the lateral chain, which was not observed in PTOBEE CA [5].

A systematic $\mathrm{CA}$ including the four torsions of the mesogen together (CO1, $\mathrm{CBO} 1, \mathrm{CO} 2, \mathrm{CBO} 2)$ was performed later. Full energy minimization was allowed during the conformational search. There were 100 sterically allowed conformers found, with an energy threshold of $10 \mathrm{kcal} / \mathrm{mol}$ above the minimum. Besides the conformers $\mathrm{AA}$ and $\mathrm{AB}$ with $E=74 \mathrm{kcal} / \mathrm{mol}$ and T-shape, two other (EB and FA) were found with lower $E$ (72 and $73 \mathrm{kcal} / \mathrm{mol}$, respectively); both were U-shaped.

The systematic CA for the four torsions defined for the spacer (head) $\mathrm{CO}$ (i.e., $\mathrm{C}_{\text {carbonyl }}-\mathrm{O}_{\text {ester }}$ ), Phi, Tau, and $\mathrm{C}^{*}-\mathrm{C}_{\mathrm{H}}$ gave 57 sterically allowed conformations after removal of duplicates, with an energy threshold of $10 \mathrm{kcal} / \mathrm{mol}$. The three minimized conformers with the lowest energy, $E=74.2 \mathrm{kcal} / \mathrm{mol}$, were selected. They resulted in a unique solution at $\left(\mathrm{CO}, \mathrm{Phi}, \mathrm{Tau}, \mathrm{C}^{*}-\mathrm{C}_{\mathrm{H}}\right)=\left(-177^{\circ}\right.$, $\left.77^{\circ}, 64^{\circ}, 179.75^{\circ}\right)$. Note the minimum value found by the program at $\mathrm{C}^{*}-\mathrm{C}_{\mathrm{H}}=$ $179.75^{\circ}$.

Molecular dynamics (MD) offers one method of conformational searching as thermal energy is introduced into the system. As it flows back and forth between various degrees of freedom, the molecule explores the potential energy surface in the neighborhood of the local minimum from which it starts. Increased simulation temperatures, although unrealistic, should be used to move over energetic barriers surrounding regions with narrow minima in the conformational space and to explore larger areas.

After an ordinary molecular dynamics simulation of the monomer molecule, a simulated annealing is advised, in which the system is deliberately heated to a high temperature ( $1000 \mathrm{~K}$ or more) to permit it to sample alternate conformations, followed by slowly cooling, or annealing, which gradually removes kinetic energy from the dynamic simulation, hence removing residual strains in a structure.

As an alternative to simulated annealing, simulated quenching, which entails a rapid drop in temperature to "freeze" the system, is also advised. Slow heating is carried out by injecting kinetic energy. As the dynamics proceeds at an elevated temperature, conformations ("snapshots") are saved at regular intervals, "frozen" abruptly by energy minimization.

Dynamical calculations with all torsions within the monomer were performed at temperatures between $1600 \mathrm{~K}$ and $500 \mathrm{~K}$, followed by quenching or annealing within the PTOBDME monomer. The more outstanding minima are shown in Table 1 . The conformer with $68.9 \mathrm{kcal} / \mathrm{mol}$ encloses the conformational 
Table 1. Torsional Angles for the Minima Energy Conformers Found by Molecular Dynamics Simulation

\begin{tabular}{lcccccccc}
\hline CO1 & CBO1 & CO2 & CBO2 & CO & Phi & Tau & C $^{*}-\mathrm{C}_{\mathrm{H}}$ & $E, \mathrm{Kcal} / \mathrm{mol}$ \\
\hline 170 & -45 & -177 & -53 & -175 & 157 & -57 & 174 & 55 \\
168 & -45 & -177 & -53 & -175 & -80.5 & -57 & -174 & 56.8 \\
171.3 & -46.7 & 179 & -52 & -173.8 & -80.9 & -56.5 & 173.5 & 57.7 \\
177.3 & 59.6 & -178.5 & 115.8 & -166.5 & -115.8 & 83.4 & 83.4 & 66.5 \\
174.3 & 53.2 & 179.7 & 50.6 & -170.2 & -160.5 & 67 & 176.2 & 68.9 \\
-166.7 & 41.8 & 178.3 & 118.7 & -162.6 & -118.5 & 77.1 & 58.3 & 71.6 \\
-165.1 & 39.2 & 178.0 & 118.8 & -163.3 & -118.4 & 74.0 & -180 & 73.5 \\
\hline
\end{tabular}

minimum found during the head CA. These were considered global minima, different from the local ones found through systematic CA, for which some torsions had been constrained to $180^{\circ}$, and lateral chain torsions were not included.

\section{Polymer Chains}

Homopolymers were built with Cerius ${ }^{2}$, with the monomer torsional values with lowest energy from the CA maps, keeping the same chirality for the $\mathrm{C}^{*}$ atom and trans connections for torsions $\mathrm{C}^{*}-\mathrm{C}_{\mathrm{H}}$ and $\mathrm{C}_{\mathrm{H}}-\mathrm{O}_{\mathrm{T}}$ to reproduce the ordered crystalline fraction observed by XRD.

Cholesteric helical molecules were obtained in all cases. Figure 8 shows the homopolymer built with 20 units from $\mathrm{T}$-shaped $\mathrm{AB}$ monomer appearing in Fig. 7A. The helicity of our models could result in the chiral behavior observed by XRD, TOA, and CD measurements.

All simulated polymer chains exhibited different helical cross sections depending on the starting monomer from which the molecule was "polymerized." Figure 9a shows the cross-sectional view along the helical axis of the polymer chain in Fig. 8. The view in Fig. 9b corresponds to a U-shaped monomer with conformation EB.

\section{Crystalline Structure Modelization}

Packing of our polymer molecules was adjusted in crystal models with Cerius $^{2}$ with the help of the experimental PTOBDME powder XRD pattern from which $\mathbf{a}$ and $\mathbf{b}$ cell parameters were estimated. All our helical polymer molecular chain models could be packed in one triclinic primitive P1 unit cell with $\mathbf{a}=5.5$ $\AA, \mathbf{b}=4.7 \AA$, $\mathbf{c}$ (equal to the pitch length of each simulated polymer helix), $\boldsymbol{\alpha}=$ $92^{\circ}, \boldsymbol{\beta}=112^{\circ}$, and $\boldsymbol{\beta}=90^{\circ}$. Molecules were oriented with their main chain parallel to the $\mathbf{c}$ axis. Figure 10 shows the asymmetric unit cell of the PTOBDME crystal structure corresponding to the polymer chain from Fig. 8. Only one cell 


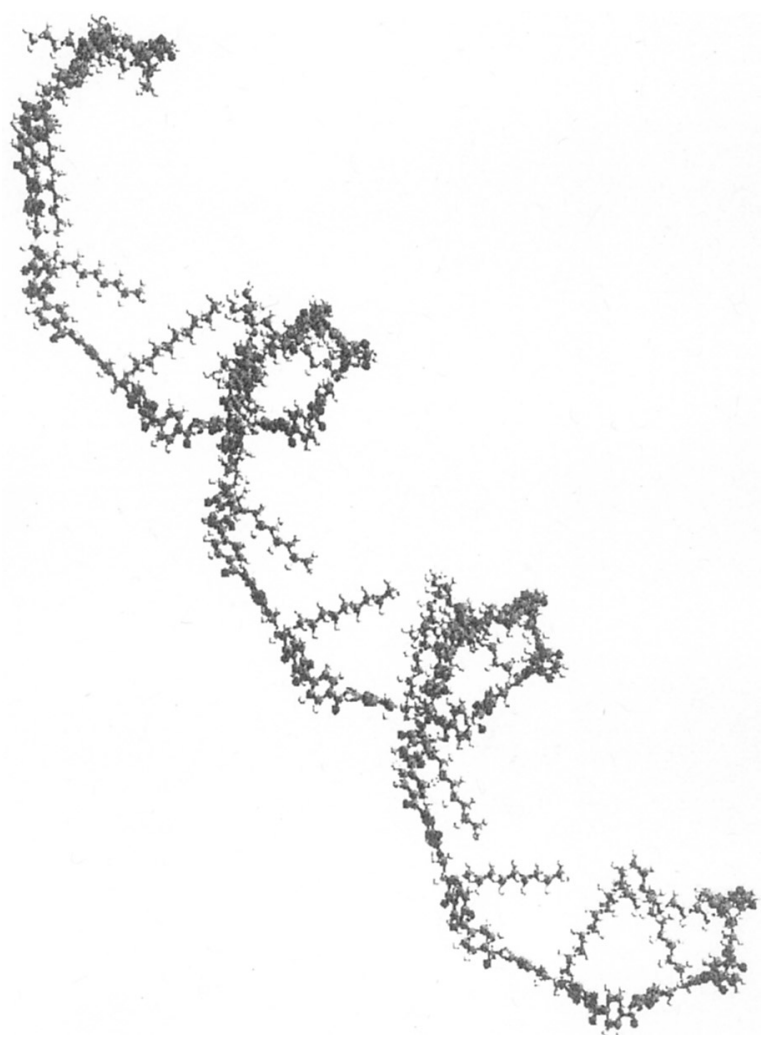

Figure 8. Poly(PTOBDME $)_{20}$ helical molecule.

has been drawn. Its content is repeated in the $x$ and $y$ directions with $\mathbf{a}$ and $\mathbf{b}$ translational vectors to build a three-dimensional polymer crystalline model.

X-ray powder diffraction patterns were recalculated for our crystal models by fitting the cell parameters of each polymer model to match the experimental one. They all matched the observed one. The simulated XRD pattern of the polymer crystal, shown in Fig. 10, appears in the square in the same figure.

The crystal morphology of our polymer crystal models was further simulated with Cerius ${ }^{2}$. The simulated morphology of the crystal appears in Fig. 10 with a rombohedral shape. It is in good agreement with the rombohedral crystals observed by optical microscopy, dispersed within the mesophase matrix (Fig. 11 ), in which some of them are indicated with arrows.

\section{Fourier Transform-Raman Analysis of PTOBDME}

In Figs. 12-I and 12-II, we show the FT-Raman spectra of PTOBDME polymer in both the solid state (b) and suspended in water (a), as well as the 


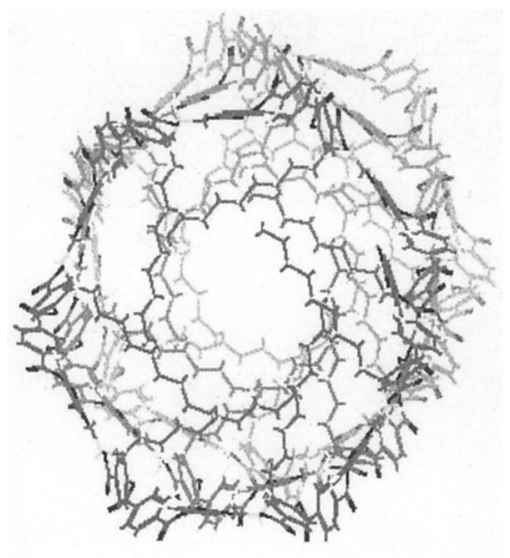

Poly[PTOBDME]20 Cage

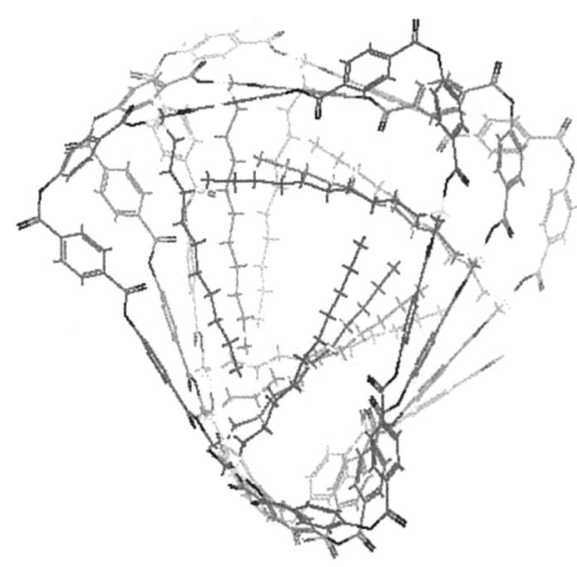

(b)

$$
\text { Poly[PTOBDME]10 Cage }
$$

Figure 9. Two different perpendicular cross-sectional views of polymer chains from different monomers.

corresponding precursors employed in its preparation: (c) TOBC and (d) DL-12-dodecanediol.

In the spectra of dry PTOBDME (Fig. 12-Ib), an intense band at $1751 \mathrm{~cm}^{-1}$ is observed that can be attributed to the terephthalate carbonyl stretching bond $v(\mathrm{C}=\mathrm{O})$. This band appears at relatively high wavenumbers compared to similar compounds reported in the literature [6,7]. A small shoulder at about $1740 \mathrm{~cm}^{-1}$ 
FAYOS ET AL.

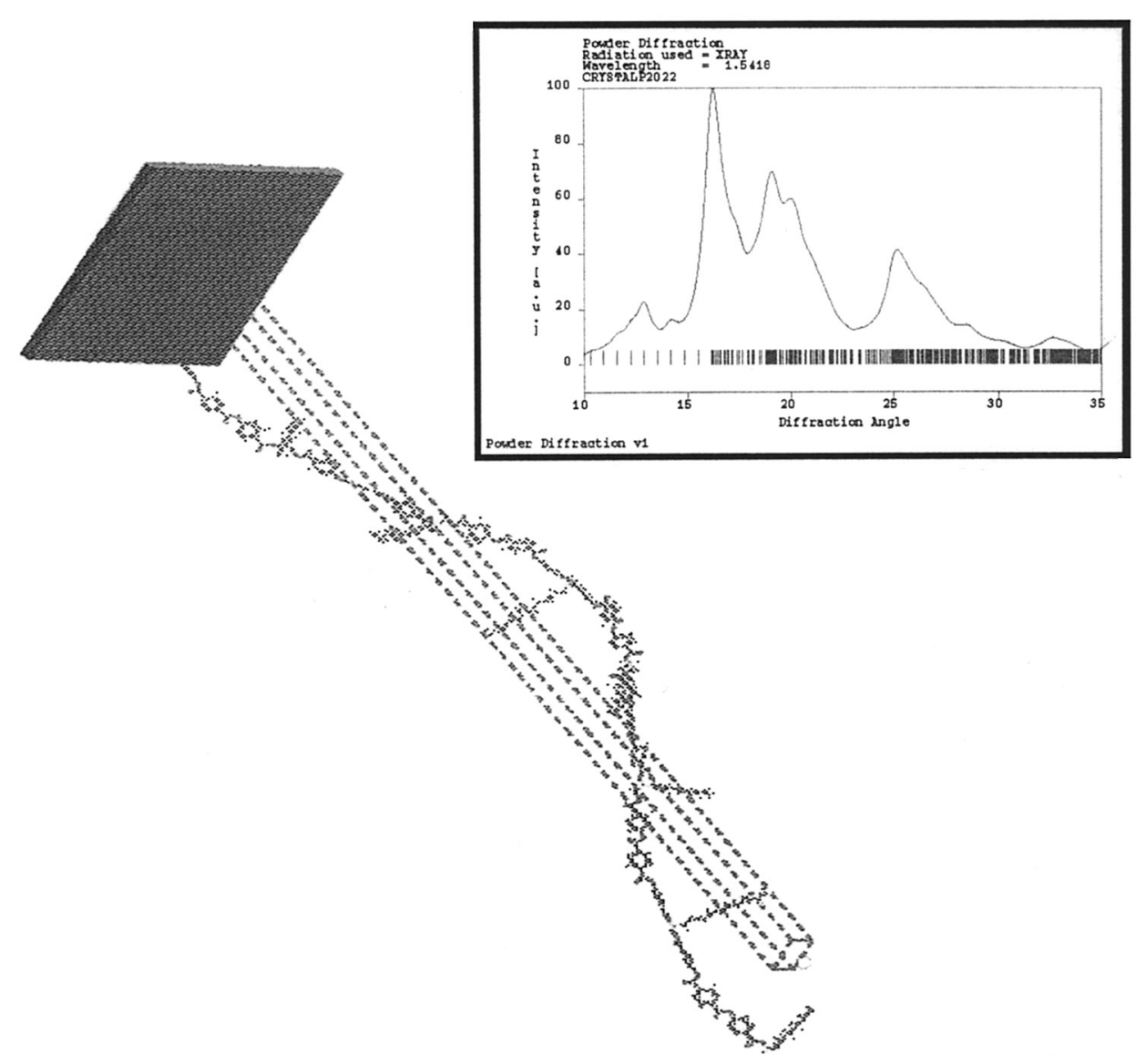

Figure 10. Crystal packing simulation of PTOBDME. Recalculated WAXS.

is interpreted as due to the oxybenzoate carbonyl group. A new band, most probably attributed to the structure of the polymer, appears at $1634 \mathrm{~cm}^{-1}$.

The strong band appearing at $1605 \mathrm{~cm}^{-1}$ was assigned to $v(C=C)$ in aromatic rings. The band at $1472 \mathrm{~cm}^{-1}$ due to methylene scissoring deformations is sensitive to conformational changes of the flexible spacer. A considerable decrease of this group is observed in the polymer with respect to the precursor DL1-2-dodecanediol (curve d).

In the region of $1350-1000 \mathrm{~cm}^{-1}$ region, the asymmetric $v(\mathrm{C}-\mathrm{O}-\mathrm{C})$ stretching vibrations of the ester groups are strongly coupled with the $v(\mathrm{C}-\mathrm{C}-\mathrm{C})$ vibrations of the aliphatic chain and $\delta(\mathrm{CH})$ of aromatic rings. Splitting of the stronger TOBC peaks in this region is observed in the polymer spectra.

In the high-wavenumber region (Fig. 12-II), an intense band appears at $3080 \mathrm{~cm}^{-1}$, corresponding to $v(\mathrm{C}-\mathrm{H})$ motions in the benzene ring. Although there is a long polymethylene moiety present in this polymer, we only observed 


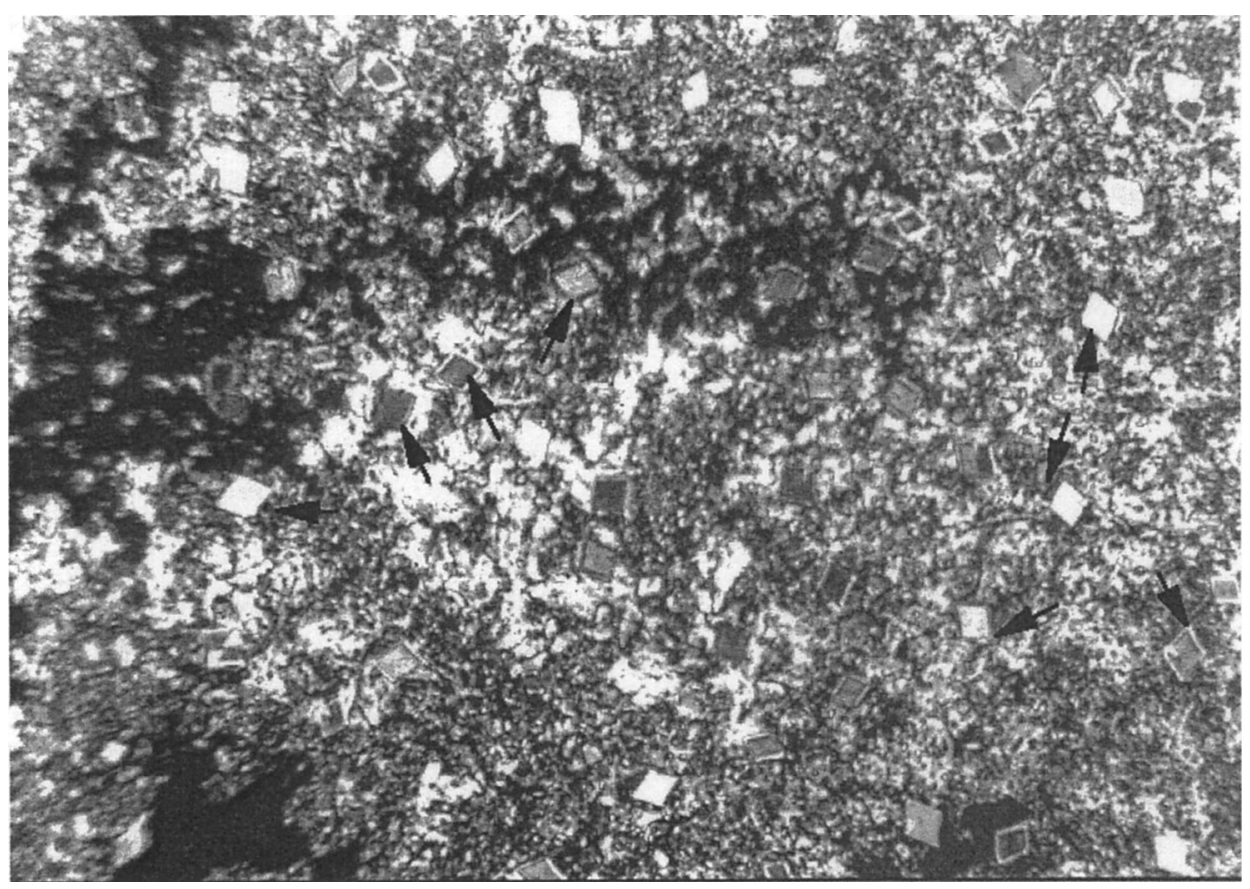

Figure 11. Optical micrograph of rhombohedral crystals of PTOBDME (some of them marked with black arrows) dispersed in mesophase matrix.

very weak bands attributed to the aliphatic $(\mathrm{C}-\mathrm{H})$ between 2800 and $3000 \mathrm{~cm}^{-1}$, even weaker when the polymer was dispersed in water, probably due to its highly hydrophobic behavior. A detailed analysis of the methylene $\mathrm{C}-\mathrm{H}$ stretching reveals a remarkable intensity increase of the $\mathrm{I}_{2930} / \mathrm{I}_{2880}$ ratio and a decrease for the $\mathrm{I}_{2880} / \mathrm{I}_{2850}$ relationship. These changes point out the existence of a more disordered structure [8].

The above Raman spectra and the changes observed in the structure marker bands are explained by the presence of helical polymer molecules and their selfassociation to form cavities. They are also observed by fluorescence when dispersed in an aqueous medium [9], in which the structure of the polymer has a more disordered state in comparison to the solid state or the precursor.

We have studied the FT-Raman spectrum of the polymer in the solid as well as in different solvents, such as water, chloroform, and deuterated dimethyl sulfoxide ( $\left.\mathrm{d}_{6}-\mathrm{DMSO}\right)$ (Figs. 13-I and 13-II). The bands corresponding to the ester moiety and the aromatic ring are very intense in Raman spectra, and they can be employed as markers to carry out a structural study of the polymer. In water, there is a doublet at 1751 and $1740 \mathrm{~cm}^{-1}$ (Fig. 13-I), which can be attributed to the $v(\mathrm{C}=\mathrm{O})$ vibration of terephthalate carbonyl and oxybenzoate carbonyl moieties, respectively. In chloroform, the lower component almost disappears or is moved upward, indicating that a conformational change is operating at the 


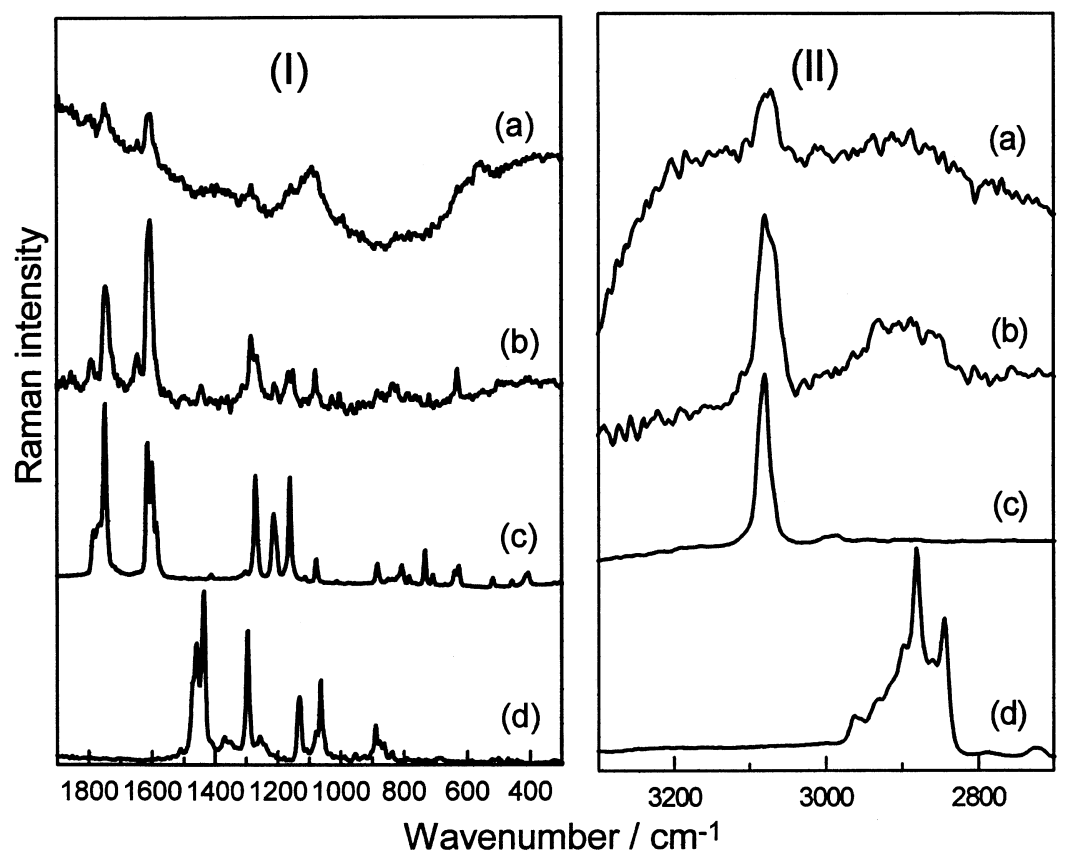

Figure 12. FT-Raman spectra of PTOBDME polymer, solid and in aqueous solution, and TOBC and DL-1-2-dodecanediol at (I) low and (II) higher wavenumber region.

level of the oxibenzoyl ester bond directly linked to the aliphatic side chain. In contrast, there is only one unique band centered at $1745 \mathrm{~cm}^{-1}$ in $\mathrm{d}_{6}$-DMSO.

The aromatic $v(\mathrm{C}=\mathrm{C})$ band is also sensitive to the polymer structure. This vibration appears as a doublet at 1614 and $1607 \mathrm{~cm}^{-1}$, with relative intensity changes that depend on the medium. In addition, we observed a shoulder at about $1634 \mathrm{~cm}^{-1}$ in this region, which is more intense in chloroform. In $\mathrm{d}_{6}$-DMSO, this shoulder is not seen, while a downshift is observed for the $v(C=C)$ vibration, and a new band is observed at $1703 \mathrm{~cm}^{-1}$.

The effect of the solvent is also manifested in the high-wavenumber region (Fig. 13-II): The band at about $3080 \mathrm{~cm}^{-1}$ reveals two components, at 3083 and $3070 \mathrm{~cm}^{-1}$, of variable relative intensity. In water and in the dried sample (previously in contact with water), there is a prominent band at $3083 \mathrm{~cm}^{-1}$ and a shoulder at $3069 \mathrm{~cm}^{-1}$. In chloroform, the intensity of this doublet is inverted, with the more intense band appearing at $3070 \mathrm{~cm}^{-1}$. However, in $\mathrm{d}_{6}$-DMSO, there again is only a single unique band centered at $3075 \mathrm{~cm}^{-1}$. As concerns the $v(\mathrm{C}-\mathrm{H})$ motions, the more remarkable changes take place in chloroform, in which a significant intensity increase is observed for the bands at 2927 and 2882 $\mathrm{cm}^{-1}$ of the aliphatic moiety. The last result is connected to a structural change in this solvent. 


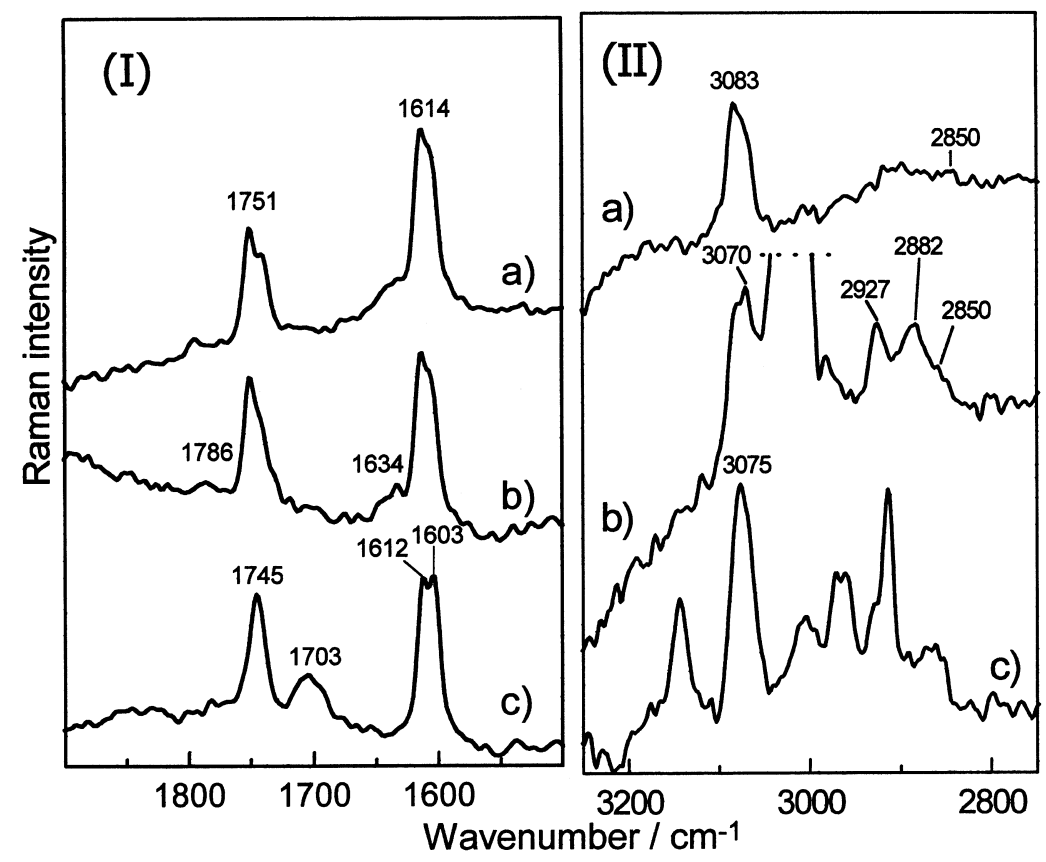

Figure 13. Effect of solvent on FT-Raman spectra of PTOBDME plus $\mathrm{d}_{6}$-DMSO, $\mathrm{CHCl}_{3}$, and water at (I) low and (II) high wavenumber region.

Structural change in $\mathrm{CHCl}_{3}$ is related to a more disordered structure, which is also connected to the solubility of the polymer in this solvent.

In the region of $1000-1500 \mathrm{~cm}^{-1}$ (Fig. 14), an intense band appearing at $1278 \mathrm{~cm}^{-1}$ is assigned to the $\mathrm{v}(\mathrm{C}-\mathrm{O})$ vibration in the ester group of the terephthalate carbonyl group, accompanied by a lower band appearing at $1267 \mathrm{~cm}^{-1}$ attributed to oxibenzoyl groups. A band appearing at $1208 \mathrm{~cm}^{-1}$, which downshifts to $1203 \mathrm{~cm}^{-1}$ in $\mathrm{d}_{6}$-DMSO, can also be assigned to a $v(\mathrm{C}-\mathrm{O})$ vibration. Likewise, the band at $1170 \mathrm{~cm}^{-1}$ undergoes shifts to $1164 \mathrm{~cm}^{-1}$ in this solvent. Below $1000 \mathrm{~cm}^{-1}$, we observed two weak bands at 760 and $839 \mathrm{~cm}^{-1}$, which can be due to the $\gamma(\mathrm{C}-\mathrm{H})$ motions in the aromatic rings. Other bands can be seen at $626,547,250$, and $120 \mathrm{~cm}^{-1}$ attributable to structural vibrations of the polymer.

The fluorescence results indicate that, in chloroform, PTOBDME self-associates to form nanocavities heterogeneous in size. Most of these structures were filtered through the $0.45-\mu \mathrm{m}$ filter, but a small fraction of PTOBDME also got through the $0.22-\mu \mathrm{m}$ filter. This fact can be related to the conformational changes deduced from the FT-Raman spectra. In chloroform, both the $(\mathrm{C}=\mathrm{O})$ and $(\mathrm{C}=\mathrm{C})$ features are shifted upward, appearing at relatively high wavenumbers, 1751 and $1614 \mathrm{~cm}^{-1}$. This result can be attributed to the adoption of a predominant nonplanar conformation of benzene rings in the mesogen, rigid moiety part of the polymer, as corresponds to the formation of coils. 


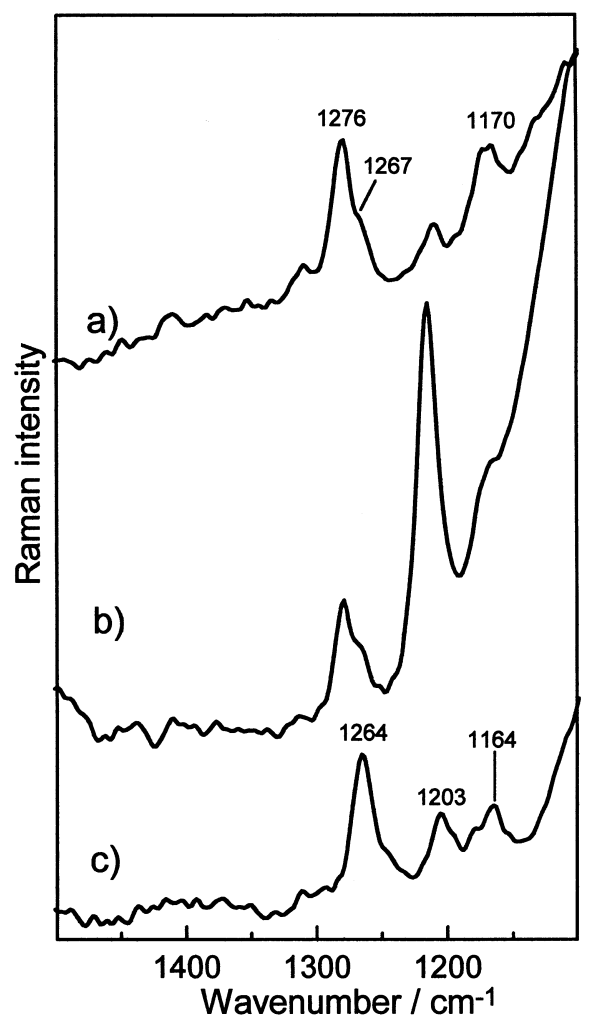

Figure 14. Effect of solvent on FT-Raman spectra of PTOBDME plus $\mathrm{d}_{6}$-DMSO, $\mathrm{CHCl}_{3}$, and water in the region between 1000 and $1500 \mathrm{~cm}^{-1}$.

\section{Simulation of PTOBDME Dispersed in a Solvent}

We have also simulated the polymer chain models of PTOBDME surrounded by different solvents, such as water and chloroform, with Cerius ${ }^{2}$ by applying Monte Carlo simulation techniques based on the Flory-Huggins theory [10].

A model for the homopolymer [PTOBDME $]_{33}$ molecule was constructed. Models for water and chloroform molecules were also built, all based on the Dreiding-II force field. Energy was minimized for all the models. Partial charges were then calculated for the models, and the energy was minimized again using the Dreiding-II force field.

The polymer molecule was sketched or loaded in the solvent molecule, with the polymer treated as a chain fragment, acting as blocking atoms in the Monte Carlo simulation.

Interaction energies $E_{11}, E_{12}, E_{21}$, and $E_{22}$ for all possible interactions $[\mathrm{PTOBDME}]_{33}$-[PTOBDME $]_{33}$, [PTOBDME $]_{33}$-solvent, solvent-[PTOBDME $]_{33}$, and solvent-solvent were then calculated. Energy distributions were plotted for 
all possible pairings, noting the equivalence of $E_{12}$ and $E_{21}$. Further, coordination numbers $Z_{11}, Z_{12}, Z_{21}$, and $Z_{22}$ were computed from model clusters.

Miscibility is determined by the energy of mixing: $\Delta E_{\text {mix }}=E_{12}-0.5\left(E_{11}+\right.$ $E_{22}$ ). Energy of mixing was determined as a function of $T$. $E_{\text {mix }}$ is dominated by local interactions between polymer segments and solvent molecules and hence is closely related to the Flory-Huggins interaction parameter $\chi_{\mathrm{HH}}^{(15)}$, chi, which is also a function of $T$.

$$
\chi_{\mathrm{FH}}=Z_{i j} V_{\mathrm{seg}}\left(\Delta E_{\text {mix/RT}}\right)
$$

Figure 15 shows these variables for a poly[PTOBDME $]_{33}$ fragment surrounded by water molecules. In Fig. 16, the same calculation results are present for PTOBDME dispersed in chloroform. Comparing the behavior of PTOBDME
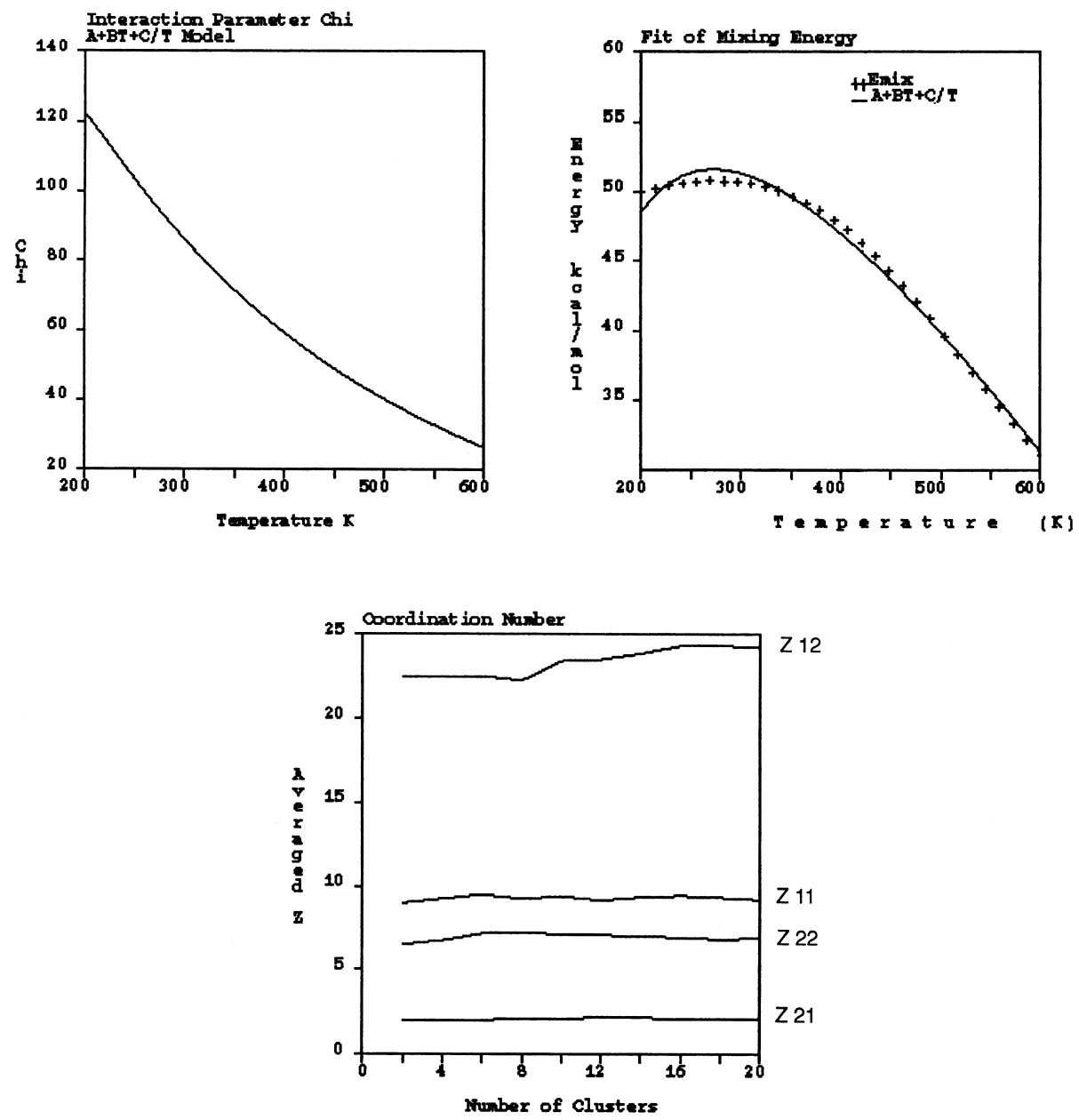

Figure 15. Interaction parameter, mixing energy, and coordination number of poly[PTOBDME $]_{33}$ dispersed in water. 

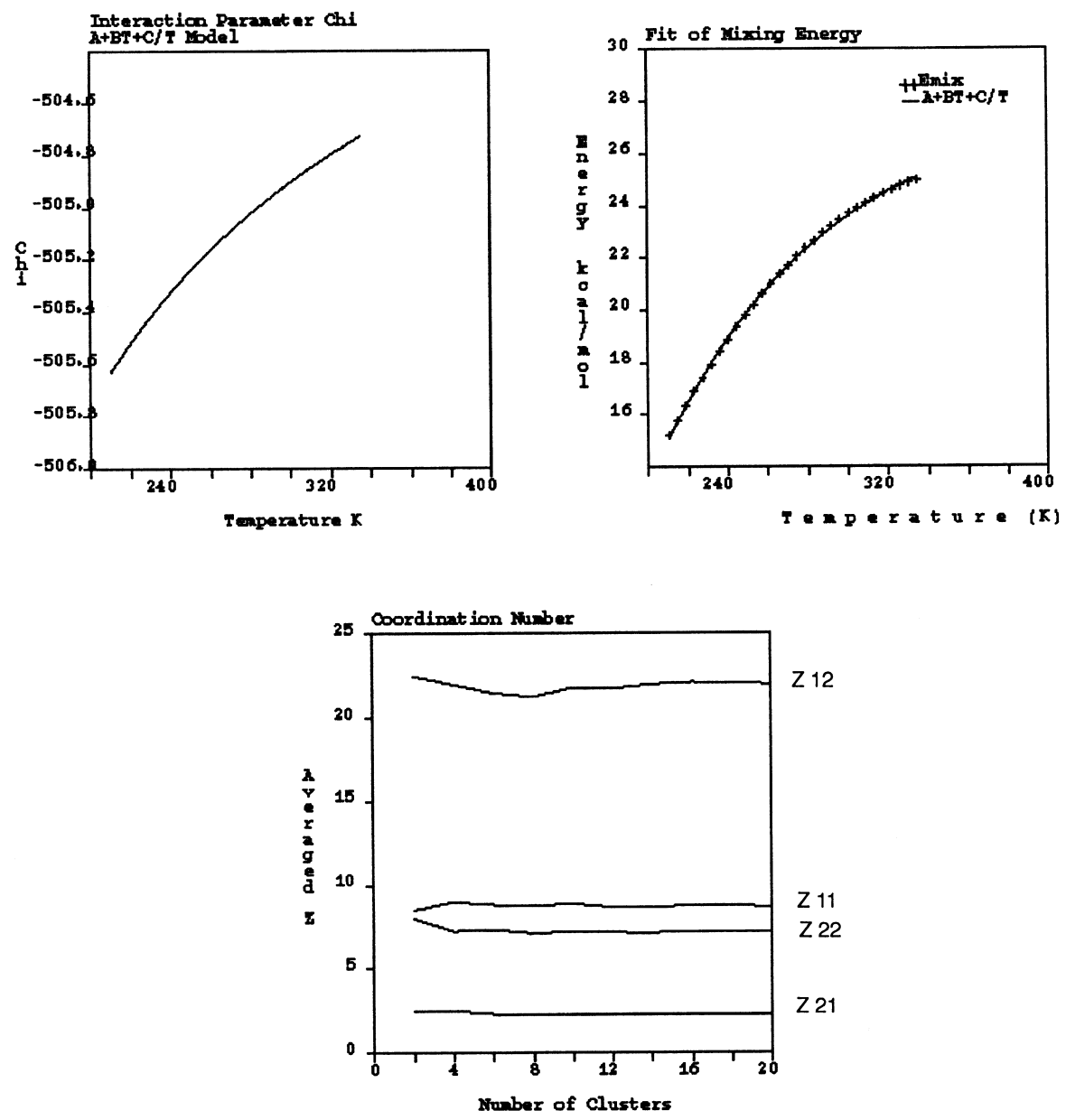

Figure 16. Interaction parameter, mixing energy, and coordination number of poly[PTOBDME $]_{33}$ in chloroform.

when dispersed in water and chloroform, we observe a tendency for the interaction parameter Chi of the polymer in chloroform to increase with temperature, while a decrease is obtained for the same variable in water. This would agree with the acceptable solubility of PTOBDME in chloroform and the highly hydrophobic character of PTOBDME.

The mixing of PTOBDME also shows opposite conduct between the two studied solvents. Hence, the model is able to forecast the opposite behavior for PTOBDME in chloroform versus water.

\section{CONCLUSIONS}

Helical cholesteric molecules were modeled for the polymer PTOBDME by molecular mechanics, systematic CA, and MD to explain its chiral behavior. 
The monomer models adopted torsional values, with minimum energy obtained by CA. After energy minimization of the whole molecule, secondary minimum energy values were also adopted by the torsions, causing the monomer to adopt a U-shape. These models are appropriate to simulate macroscopic properties experimentally observed. Crystal packing was simulated in cells, with the parameters $\mathbf{a}$ and $\mathbf{b}$ obtained from the experimental XRD and with calculated from theoretical "polymerization." Molecules were oriented with their main chains parallel to the c axis. Calculated XRD patterns from these models were in good agreement with the observed one. The morphology calculated from the simulated crystals was able to reproduce the rombohedral shape of crystals observed by optical microscopy dispersed in the cholesteric mesophase matrix.

FT-Raman spectra of PTOBDME were analyzed in detail, both in the solid state and when dispersed in different solvents (water, chloroform, and deuterated dimethyl sulfoxide). Evidence for the self-associating nature of the cholesteric liquid crystal PTOBDME in aqueous media, observed by fluorescence, was obtained from Raman spectra; changes in the structural marker bands of both aliphatic and aromatic moieties in chloroform reflect a conformational change in this solvent. Simulation of the interaction parameter and mixing energy of PTOBDME in water and chloroform confirms this behavior and the highly hydrophobic character of PTOBDME. It also explains the acceptable solubility of PTOBDME in chloroform.

\section{ACKNOWLEDGMENT}

This work was partly funded by the Spanish MEC through its SAF19980073-CO2-02 Plan Nacional de I+D Project.

We thank the European Union for support of the work at DESY Hamburg through the HCMP Access to Large Installations Project (Contract CHGE-CT930040).

\section{REFERENCES}

1. Pérez-Méndez, M.; Marco, C. New Synthesis, Thermal Properties and Texture of Cholesteric Poly[oxy(1,2-butene)oxycarbonyl-1,4-Phenyleneoxycarbonyl-1,4-phenylenecarbonyloxy-1,4-phenylenecarbonyl], PTOBEE. Acta Polym. 1977, 48, 502506.

2, Marco, C.; Pérez-Méndez, M. Kinetics of Isothermal Crystallization of Thermotropic Polyester Poly[ethylethylene-4,4-diphenoxyterephthalate). J. Thermal Anal. 1998, 53, 35-47.

3. Pérez-Méndez, M.; Marco Rocha, C. Process for Obtaining Cholesteric Liquid Crystals by Stereoselective Recrystallization. US Patent 6165382, December 26, 2000.

4. Purdie, N.; Brittain, H. G. Analytical Applications of Circular Dichroism. In Tech- 
niques and Instrumentation in Analytical Chemistry; Purdie, N.; Brittain, H.G., Eds.; Elsevier: Amsterdam, 1994; Vol. 14, 104-108.

5. Fayos, J.; Pérez-Méndez, M., to be published.

6. Boerio, F.J.; Bahl, S.K.; McGraw, G.E. Vibrational Analysis of Polyethylene Terephthalate and Its Deuterated Derivatives. J. Polym. Sci., Polym. Phys. Ed. 1976, 14, 1029-1046.

7. Benedetti, E.; Galleschi, F.; Chiellini, E.; Galli, G. Infrared Study of Phase Transitions in Thermotropic Liquid Crystal Polyesters. J. Polym. Sci., Part B: Polym. Phys. 1989, 27, 25-37.

8. Wong, P.T.T.; Siminovich, D.J.; Mantsch, H.H. Structure and Properties of Model Membranes: New Knowledge from High-Pressure Vibrational Spectroscopy. Biochim. Biophys. Acta 1988, 947, 139-171.

9. Pérez-Méndez, M.; Fayos, J.; Mateo, R. Self-Assembly of Cholesteric Liquid Crystal Polyesters and Their Stereoselective Interaction with Liposomes of DMPC. In Advances in BioChirality; Pályi, G., Zucchi, C., Caglioti, L., Eds.; Elsevier Science S.A.: Oxford, UK, 1999; chap. 24.

10. Flory, J. Principles of Polymer Chemistry; Cornell University Press: Ithaca, NY, 1953.

Presented September 28, 2000

Revised March 7, 2001

Accepted March 7, 2001 


\section{Request Permission or Order Reprints Instantly!}

Interested in copying and sharing this article? In most cases, U.S. Copyright Law requires that you get permission from the article's rightsholder before using copyrighted content.

All information and materials found in this article, including but not limited to text, trademarks, patents, logos, graphics and images (the "Materials"), are the copyrighted works and other forms of intellectual property of Marcel Dekker, Inc., or its licensors. All rights not expressly granted are reserved.

Get permission to lawfully reproduce and distribute the Materials or order reprints quickly and painlessly. Simply click on the "Request

Permission/Reprints Here" link below and follow the instructions. Visit the U.S. Copyright Office for information on Fair Use limitations of U.S. copyright law. Please refer to The Association of American Publishers' (AAP) website for guidelines on Fair Use in the Classroom.

The Materials are for your personal use only and cannot be reformatted, reposted, resold or distributed by electronic means or otherwise without permission from Marcel Dekker, Inc. Marcel Dekker, Inc. grants you the limited right to display the Materials only on your personal computer or personal wireless device, and to copy and download single copies of such Materials provided that any copyright, trademark or other notice appearing on such Materials is also retained by, displayed, copied or downloaded as part of the Materials and is not removed or obscured, and provided you do not edit, modify, alter or enhance the Materials. Please refer to our Website User Agreement for more details.

\section{Order now!}

Reprints of this article can also be ordered at http://www.dekker.com/servlet/product/DOI/101081MB100106177 